\title{
Optimization Model Construction of Unemployment Insurance
}

\author{
${ }^{1, a}$ Wen Haihong $\quad{ }^{2, b}$ Niu Yuqiong $\quad{ }^{3, c}$ Song Xin \\ ${ }^{1}$ College of Humanities and Social Sciences, Xi'an Jiao Tong University, Xi'an, ShanXi 710049, \\ China \\ 1,2,3 College of public policy and management, Xi'an Jiao Tong University, Xi'an, ShanXi 710049, \\ China
}

\begin{abstract}
ahelenwen@mail.xjtu.edu.cn b2750731491@qq.com ${ }^{\mathrm{c}}$ 1351807219@qq.com
Keywords: Unemployment insurance, optimization model, fixed payment, digression payment.

\section{Abstract.}

This paper makes theoretical analysis based on the unemployment insurance optimization design of employment promotion, constructs the optimization model and theoretical hypothesis of employment insurance with the re-employment bonus as variable factor, and makes empirical research with the application of the registration data of the unemployed in Qingdao; on this basis, relevant policy suggestions are put forward from different perspectives and provides theoretical and empirical references for rational design of the unemployment insurance in our country.
\end{abstract}

\section{Introduction}

Unemployment insurance is the important component of social security system[1,2,]. It can ensure the basic life of the unemployment and avoid risks; but at the same time, it will bring certain negative effect to the unemployed with some preferences during leisure time, reduce the job hunting degree, prolong the duration time, lower the re-employment rate, so as to increase the social cost. Therefore, a good unemployment insurance mechanism should not only have sufficient supportive capacity to guarantee the basic living to the un-employed, but also hold the appropriateness of insurance level, so as to prompt vigorous re-employment of the unemployed, reaching balance between guarantee and efficiency[3,4]. Problems in the aspect of un-employment insurance imposition mainly include: narrow coverage of un-employment insurance, low imposition rate, unfavorable setting of personal payment base for low income earners, long cycle of un-employment insurance payment, low payment level and shortage of dual distribution, and low proportion in the expenses of unemployment insurance fund for unemployment prevention and re-employment promotion. Domestic scholars think that the influence of population change in urban and rural structure on the demand of unemployment insurance are mainly manifested in three aspects. The first one is that the change of population change in urban and rural structure influences the coverage of unemployment insurance. Through the investigation of the unemployment in five cities, some scholars point out the influence of population mobility on the insured scale of unemployment insurance[5]. Some people believe that canceling household registration system boundary is necessary for the expansion of unemployment insurance coverage. The second one is that the unemployment insurance fund expenditure is influenced by population change in urban and rural structure. The total of unemployed population equals the product of laboring population covered by unemployment insurance times unemployment rate; and under the circumstance of specific unemployment insurance, with the change of population change in urban and rural structure, the increase of unemployed population will bring about the increase of expenditure of unemployment insurance fund[6]. The third one the actuarial studies on the balance between supply and demand of unemployment insurance fund. Wang Yiqun et al. takes the factor analysis of unemployment insurance fund as a view, and makes short-term predictions on the balance of payment of unemployment insurance fund in Beijing through building the incomes and outgoings prediction model and balance model of unemployment insurance fund.

This paper uses the unemployment registration data in Qingdao, simulates the three models of fixed payment of unemployment insurance with time, digressive payment and payment which increases first and then decreases with introduction of re-employment bonus, and compares results. Through 
analysis, it can be obtained that the fixed unemployment insurance payment system in operation at present is not the best, and can be improved and made breakthroughs to a great degree; from the perspectives of saving government cost, prompting employment and welfare of the unemployed, the payment model of re-employment bonus which increases first and then decreases is obviously superior to the fixed payment model and digressive unemployment insurance payment model. The empirical research proves the theoretical hypothesis put forward in this paper.

\section{Theory construction of the influence of unemployment insurance}

Unemployment insurance demand: Unemployment insurance demand is the capital total resulted from the existence of unemployment risks and expected to gain for maintaining the basic living at a certain time without considering the constraint conditions of present unemployment insurance system, and it is decided by the economic development level and the degree of social development. The factors influencing unemployment insurance demand can be divided into within system and out of system: factors within system refers to the variables that can be influenced or changed through building and adjusting unemployment insurance system; factors out of factors refers to the variables that can not be influenced or changed. The factors within system influencing employment insurance demand mainly means the level of unemployment insurance treatment. According to regulation on unemployment insurance, it can be further broken up into unemployment insurance, medical assistance payment, funeral assistance payment, support pension, and re-employment subsidy; factors out of system influenced by unemployment insurance demand is mainly the total unemployment, which can be further divided into labor force and unemployment rate in cities and towns, which can be seen in Table 1.

Table 1: Variable system of unemployment insurance demand

\begin{tabular}{|c|c|c|}
\hline First level index & Second level index & Third level index \\
\hline \multirow{7}{*}{$\begin{array}{l}\text { Unemployment } \\
\text { insurance demand D }\end{array}$} & \multirow{5}{*}{$\begin{array}{l}\text { Unemployment } \\
\text { insurance benefits } \\
\text { B }\end{array}$} & Unemployment insurance benefits B1 \\
\hline & & Medical subvention demand B2 \\
\hline & & Funeral subvention demand B3 \\
\hline & & Support pension demand B4 \\
\hline & & Re-employment subsidy demand B5 \\
\hline & \multirow{2}{*}{$\begin{array}{ll}\text { Number } & \text { of } \\
\text { unemployment } & \\
\text { people P } & \end{array}$} & Labor force L \\
\hline & & Unemployment rate $\mathrm{U}$ \\
\hline
\end{tabular}

Basic theoretical model of unemployment insurance optimization: As is shown in Table 1, B1 is the expected discount total of insurance paide for every unemployed person by the government.

$B_{t}=\sum_{t=1}^{\infty} b_{t} \prod_{j=1}^{t-1}\left(1-p_{j}\right) /(1+r)^{t-1}$

The unemployed person gains insurance benefit $b$ tat phase $t$, and gained utility from bt consumption is $U(b t)$. without considering the negative effect caused by unemployed work search, the wage level of re-employment of every term is $\mathrm{w}$, and then the total expected utility discounted present value at this time is:

$$
E_{t}=\left[\sum_{t=1}^{\infty} p_{t} \prod_{j=1}^{t-1}\left(1-p_{j}\right)\right]\left[\sum_{j=1}^{t} U\left(b_{j}\right) /(1+r)^{j-1}+U(w)\left(r(1+r)^{t-1}\right)\right]
$$

As unemployed people can decide the probability of re-employment through choosing search intensity and keeping wage level, the re-employment probability and expected utility ut at term t are both the function of retained wage wt and search intensity et; as the government cannot monitor the search intensity and retained wage level of the unemployed, the optimality principle of unemployment insurance is: under the limiting condition of fixed $\mathrm{Bt}$, if the expected utility of unemployed people is maximized, $\mathrm{Et}+1$ satisfies: 


$$
E_{t}=\max _{w_{t}, e_{t}}\left\{U\left(b_{t}\right)-e_{t}+[1 /(1+r)]\left[p\left(w_{t}, e_{t}\right) u w_{t}, e_{t}\right)+\left[1-p\left(w_{t}, e_{t}\right)\right] E_{t+1}\right\}
$$

The first order condition of this maximization is:

$$
\begin{aligned}
& \frac{\partial E_{t}}{\partial e_{t}}=-1+1 /(1+r)\left[p_{e}\left(u-E_{t+1}\right)+p u_{e}\right]=0 \\
& \frac{\partial E_{t}}{\partial w_{t}}=1 /(1+r)\left[p_{w t}\left(u-E_{t+1}\right)+p u_{w t}\right]=0
\end{aligned}
$$

It can be gained through analyzing maximization conditions:

$$
\frac{d p_{t}}{d b_{t+1}}=\frac{d p_{t}}{d E_{t+1}} U^{1}\left(b_{t+1}\right)<0
$$

From the formula above, it can be seen that the probability of re-employment in this term is closely related to the insurance payment of next term; if the insurance payment of next term increases, the next expected utility of unemployment people will increase; therefore, the re-employment probability of this term will decrease. In other words, any government behaviors that can increase the expected utility of unemployed people in next term will make the search intensity of the unemployed people at this term decrease, and then make the re-employment probability decrease. The decreased insurance payment will make the re-employment probability increase progressively.

If re-employment bonus $\mathrm{Sn}$ is introduced, suppose government stipulates that re-employment bonus within certain terms should be provided, the amount is inversely proportional to the layoff, which means the earlier the unemployment is, the more is the bonus; then, after $n$ terms, the expected utility of re-employed unemployed people is the same as the expected utility when there is no re-employment bonus parameter, which is:

$$
E_{t}=\sum_{k=t}^{\infty}\left(\left[P_{k} \prod_{j=1}^{k+1}\left(1-p_{j}\right)\right]\left\{\sum_{j=t}^{\infty}\left(U\left(b_{j}\right)-e_{j}\right) /(1+r)^{j-t}+u_{k} /(1+r)^{t-1}\right\}\right)
$$

Unemployment insurance payment sequence is not monotonous, which should increase first and then decrease. It means that during the first $\mathrm{n}$ terms, as the re-employment bonus decreases degressively, the payment of unemployment insurance should not be too much, and it will increase slowly; after $\mathrm{n}$ terms, the insurance payment decreases monotonously.

Theoretical assumption: In the aspect of employment promotion, the decreasing unemployment insurance model is better than the fixed payment model; in the aspect of unemployed people's welfare, under the same condition of unemployment cost, comparing with fixed payment, decreasing payment will surely increase the welfare of the unemployed people in short term, and the welfare of unemployed people of long term will relatively decrease. Moreover, re-employment bonus is introduced, which is different from normal unemployment insurance, and every unemployed person with unemployment insurance has the right to have it equally; but re-employment bonus is different, which is a kind of extra encouragement and award for re-employed people, and only those making efforts both objectively and subjectively are qualified to have it; therefore, in the aspect of employment promotion, it will be superior to the pure decreasing payment model, and the re-employment rate within re-employment time will at least increase largely; in the aspect of welfare, within the re-employment bonus time limit, the starting point of unemployment insurance payment is very low, and it will increase degressively at the low starting point; although insurance payment is relatively low compared with decreasing payment, most of unemployed people will get a job within short time as a result of re-employment bonus, and this is the biggest guarantee, and the welfare of unemployed people will surely increase. Besides the re-employment bonus, the insurance payment starts decrease and is the same as pure decreasing payment, and therefore, the total welfare of unemployed people of long term should also be higher than decreasing payment model.

\section{Selection of optimal unemployment insurance model}

Data description and disposition: The data comes from registered information database of unemployed people in Qingdao Labor and Social Security Bureau, and this database includes detailed registered information of urban unemployed people in Qingdao since the new regulation on 
unemployment insurance in 1999. Compared with the survey data of unemployed (households), unemployment registered data has large amount of personal information, especially the personal information of unemployed people is rather exact; and through detailed registered unemployment time and failure time of unemployment certificate, the unemployment duration can be calculated approximately. This paper takes the unemployed people with insurance benefit qualification starting to register since 2003 as sample, which can ensure the consistency of the labor market environment of the sample and avoid the interference of business cycle factor to certain degree. In order to ensure the consistency of labor market faced by the unemployed people and the comparability among the unemployed people and reduce the influence of mixed factors such as the uneployment people's features, only the "employed to unemployed people" which takes the main part are chosen. In the samples, abnormal data (samples with negative values after statistics during unemployment time) are deleted, and there is information with 22152 unemployed people in the final sample. Through statistics, the average unemployment time of those people with unemployment insurance in Qingdao is 7.2 months.

Contrastive analysis of three unemployment insurance models: This paper concludes three types of typical payment models, which are fixed payment model, decreasing payment model and payment model introducing re-employment bonus which increases first and the decreases. This paper makes comparative analysis from following three aspects.

(1) Comparison of re-employment of the unemployed people under three unemployment insurance models

The incentive function of payment model decreasing progressively on the re-employment of unemployed people within short term is not very effective, because this model increases the welfare of unemployed people of short term to certain degree; the increase of the short-term effect allows unemployed people to enjoy conditional leisure time within short time. While the introduction of re-employment bonus avoids this kind of malpractice to certain degree, and makes the unemployed people overcome the willing of conditional leisure subjectively so as to search for a job actively. Figure 1 can be referred to for clearer observation. Obviously, from the perspective of employment promotion, the payment model which increases first and then decreases introducting re-employment bonus is definitely better than the unemployment insurance model which decreases progressively. From the aspect of employment promotion, fixed unemployemnt insurance payment model $<$ unemployment insurance payment model decreasing progressively < unemployment insurance payment model introducing re-employment bonus which increases first and then decreases

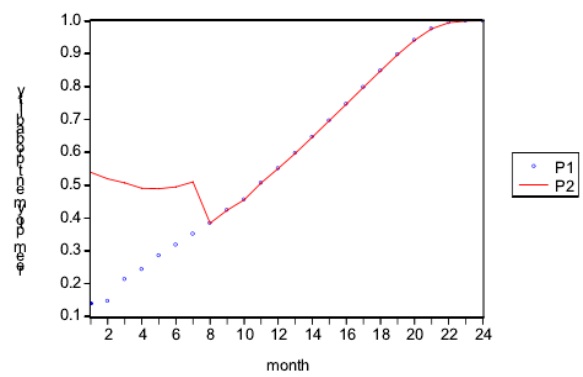

Figure 1 Re-employment rate comparison between payment model decreasing progressively and payment model introducing re-employment bonus which increases first and then decreases

(2) Comparison of unemployed people's welfare level under three unemployment models

Whether in short or long term, the welfare level of unemployed people of long term under re-employment bonus model is far higher than that of unemployed people of long term under the model decreasing progressively. Comparing with fixed payment model, the payment model decreasing progressively increases the welfare of unemployed people's welfare, but the welfare of unemployed people's welfare of long term relatively decreases. For convenient comparison, Table 2 is as following: 
Table 2: Comparison of unemployment insurance cost and unemployed people's welfare level under three unemployment insurance models

\begin{tabular}{|l|l|l|l|l|l|l|}
\hline \multirow{2}{*}{$\begin{array}{l}\text { Unemployment } \\
\text { insurance } \\
\text { payment model }\end{array}$} & \multicolumn{2}{|l|}{$\begin{array}{l}\text { Unemployment } \\
\text { insurance cost }\end{array}$} & Short term & $\begin{array}{l}\text { Lolfare level of } \\
\text { unemployed people } \\
\text { term }\end{array}$ & Short term & \multicolumn{2}{|l|}{$\begin{array}{l}\text { Lncreasing rang term } \\
\text { welfare }\end{array}$} & $\begin{array}{l}\text { Short } \\
\text { term }\end{array}$ & Long term \\
\cline { 2 - 7 } & 2.673 & 2.802 & 0.773 & 0.979 & $0 \%$ & $0 \%$ \\
\hline $\begin{array}{l}\text { Fixed payment } \\
\text { decreasing } \\
\text { progressively }\end{array}$ & 2.673 & 2.802 & 0.844 & 0.971 & $9.2 \%$ & $-0.828 \%$ \\
\hline $\begin{array}{l}\text { Re-employment } \\
\text { bonus }\end{array}$ & 1.4907 & 1.497 & 1.186 & 1.193 & $53.4 \%$ & $21.9 \%$ \\
\hline
\end{tabular}

\section{Conclusion and policy significance}

Firstly, the unemployment insurance system of fixed payment implemented presently in our country is not the best, which can be improved or made breakthroughs to a large extent no matter from the perspective of employment promotion or the welfare of unemployed people. Secondly, under the condition of the same unemployment insurance cost, from the perspective of employment promotion and the welfare of unemployed people in short time, payment model decreasing progressively is superior to fixed payment model, as the payment model decreasing progressively not only stimulates the search force of the unemployed people and drives the employment turning rate up, but also increases the welfare of unemployed people's welfare. As for the welfare of unemployed people's welfare, comparing with fixed payment model, payment model decreasing progressively reduces the welfare of unemployed people in long term. Thirdly, the payment model introducing re-employment bonus which increases first and then decreases is apparently better than fixed payment and payment model decreasing progressively.

The substantial increase of unemployed people's welfare of short term has its disadvantages at the same time, which will causes some other problems, such as it will increase other choices for those employed people who are unsatisfied with present work and are on the borderline of employment and unemployment, and it will also intensifies unemployment; moreover, if worker don't have the right and ability to negotiate salary, the unemployment insurance payment increasing progressively will undoubtedly increase the salary pressure, as the failures in negotiation will make workers in negotiation become unemployed people of short time and qualified to enjoy unemployment insurance with high welfare, which will also intensify unemployment to certain degree and disturb the price balance in labor force market. However, as a whole, the advantages are more than disadvantages, especially under the circumstances of the severe employment pressure in our country, the wise employed people who are unsatisfied with present job will not choose to quit job abruptly; on the other hand, the negotiation consciousness of employed people in our country is very weak and they have no place to negotiate under this kind of employment pressure. Therefore, these two disadvantages won't have influence on the employed people in our country.

The research basically verifies the theoretical hypothesis in this paper. At the same time, revisions should be made on the original model in some aspects: this model supposes the same characters of all the workers, which means same work efficiency and work time, and they are all risk averters, workers' employment state is absorption state, and it means that as soon as workers accept a job, they will work forever without quitting or dismissal, which doesn't suit present state to a large degree; secondly, this model considers the moral risk of unemployed people, but it only shows the existence of this kind of moral risks through supposing that government doesn't monitor unemployed people's personal searching behaviors. This kind of moral risks come from the search intensity of unemployed people without involving other moral risks, such as task performance of employed people after responses under certain unemployment insurance system, unregistered employment and insurance fraud behaviors of unemployed people, and so on. All of these influence the exactness of our 
analyzing results to certain degree. Therefore, it is necessary to build better theoretical model, to make more exact theoretical and empirical analysis.

To make proper payment time sequence according to our state condition is favorable for stimulating unemployed people's search intensity and accelerating employment. On the other hand, government can use small part of unemployment insurance budget as subsidy to provide for companies, so as to gain more employment opportunities and reduce labor supply pressure; the government can also take a small part as re-employment bonus to stimulate active re-employment of unemployed people. Moreover, as the number of unemployed people is large, government cannot observe the behaviors of unemployed people; the adoption of supervision mechanism will cause large cost; thus, it is believed that welfare policy will be a very effective method in our country, as it can automatically screen out the group who should gain unemployment insurance and compensate them; the other unemployed people can be given basic cost of living allowances, which can not only save government cost but also reach the unity of guarantee and efficiency.

\section{References}

[1] Hua Ming. Exploration on the unemployment insurance issues of floating population in our country [J] Wuxi Business Vocational Technical Institute Journal, 2007,7(3):41-43.

[2] Yin Jun. Influencing factors of unemployment insurance system demand of land-lost farmers and project design [J]. Contemporary economy and management, 2014,36(8):87-91

[3] Beveridge. Beveridge report: social insurance and relevant service [M]. Beijing: Chinese labor and social security press, 2008.

[4] Zheng Gongcheng. Chinese social security reform and development strategy (Overview) [M]. People’s Publishing House, 2011.

[5] Sun Jie, Gaobo. Existing problems and reform thought of unemployment insurance system in our country [J]. Northwest Normal University Journal (social science edition), 2011，48(1): 122-127.

[6] Zhang Jingzeng. Research and thought on employment promotion and stablization of unemployment insurance in Heze [J]. Value engineering, 2011, 30(8): 189-190.

[7] Li Xiaojuan. Discussion on the problems and solutions of unemployment insurance system in our country [J]. Foreign investment in China, 2011, (3): 34.

[8] Han Wei, Xu Lei, Mu Huaizhong, Zhu Xiaoling. Research on peasant-worker unemployment insurance system [J]. China Soft Science, 2010,8

[9] Zhang Nengqiang. Operation study on unemployment insurance system - Yunnan province as example [D]. Yunnan Unicersity of Finance, 2011. 